\title{
The effect of varying amounts of intravenous glucose on the metabolic changes after surgery
}

\author{
R. SWAMINATHAN \\ M.B., Ph.D., M.R.C.Path. \\ G. H. HILL \\ M.B., Ch.B., F.R.A.C.S.
}

J. A. BRAdley

M.B., Ch.B.

D. B. Morgan

M.D., M.R.C.Path.

Departments of Chemical Pathology and Surgery, University of Leeds

\begin{abstract}
Summary
The metabolic effects of saline, $30 \mathrm{~g}$ of glucose a day and $129 \mathrm{~g}$ of glucose a day were studied in patients after either cholecystectomy or highly selective vagotomy. In the saline group the blood ketone concentration increased to $3.3 \mathrm{mmol} / \mathrm{l}$ on the 5 th day after surgery, but this increase was completely abolished by a daily intake of $129 \mathrm{~g}$ of glucose and almost completely so by $30 \mathrm{~g}$ of glucose. Urine nitrogen excretion expressed as nitrogen to creatinine ratio in the saline group increased from 42.5 to 66.2 by the third day after surgery, and there was a similar increase in the group given $30 \mathrm{~g}$ a day of glucose. However, $129 \mathrm{~g} /$ day of glucose completely prevented the increase in urine nitrogen, an effect which is similar to that reported in starving subjects given similar amounts of glucose. It is suggested that $129 \mathrm{~g}$ of glucose only prevents that part of the increase in nitrogen excretion which is due to starvation and that it has no effect on the increase in nitrogen excretion which happens as part of the metabolic response to surgery.
\end{abstract}

\section{Introduction}

After surgery, as during starvation, there is an increase in the concentration of ketone bodies in the blood (Benotti et al., 1977; Craig et al., 1977), and a loss of nitrogen from the body (Cuthbertson, 1936; Moore, 1953).

Glucose ( $150 \mathrm{~g} /$ day) prevents the increase in ketone bodies in the 3 to 4 days after surgery (Benotti et al., 1977; Craig et al., 1977) and abolishes the ketosis during starvation (Aoki et al., 1975). The same amount of glucose reduces the nitrogen loss during starvation, but there are conflicting conclusions about its effect on nitrogen loss after surgery (Benotti et al., 1977; Craig et al., 1977).

This paper describes the effects of $129 \mathrm{~g} /$ day of glucose and $30 \mathrm{~g} /$ day of glucose on the metabolite $\mathrm{N}$ concentrations and urine nitrogen in patients after 윽 moderate uncomplicated surgery in order to clarify $\vec{c}$ the conflicting results reported in the literature. The $\mathbb{D}$ study was extended beyond 3-4 days until oral feeding was started on the 5th or 6th day.

\section{Patients}

Twenty-one patients were studied after electi递 abdominal surgery of moderate severity (chole: cystectomy or highly selective vagotomy). None of o the patients had diabetes or hepatic or renal failure. All the patients had an uneventful postoperative recovery without sepsis. None of the patients received heparin during the study. Patients were $\varnothing$ allocated to 3 groups. There were 5 males and $2 \underset{7}{\Rightarrow}$ females in each group.

\section{Protocol}

Each patient was given 3 litres of fluid intravenously daily from the day of operation until the resumption 3 of eating 5-6 days later. The saline group received $0.9 \%$ saline, the second group received $1 \%$ dextrose 3 . with $0.72 \%$ saline ( $30 \mathrm{~g}$ of glucose a day) and the 8 third group received $4.3 \%$ dextrose with $0.18 \%$ saline (129 $\mathrm{g}$ of glucose a day).

Blood samples were taken between 8 a.m. and $\frac{\text { a }}{7}$ 9 a.m. each morning. Two $\mathrm{ml}$ of blood was added immediately to $2 \mathrm{ml}$ of $10 \%$ trichloracetic acid in hydrochloric acid for the measurement of ketones, $\sigma$ glycerol and alanine. Consecutive 24-hr urine collec- No tions were made from the day of operation (day 0 ) $\underset{\mathrm{C}}{N}$ for the measurement of nitrogen (urea plus ammonia) and creatinine.

Blood glucose was measured by an automated $\frac{0}{\frac{C}{D}}$ glucose oxidase method. Blood ketone bodies $\stackrel{\oplus}{-}$ (acetoacetate and $\beta$-hydroxybutyrate) and alanine $\square$ were determined enzymatically by a semi-automated ${ }_{0}^{\circ}$ 
method using an LKB reaction rate analyser (Annan, 1974). Glycerol was also measured on an LKB reaction rate analyser using glycerol kinase. Urine nitrogen, measured as the sum of urea and ammonia, and urine creatinine were determined on a Vickers multichannel analyser M300. Urine nitrogen results were expressed as nitrogen/creatinine ratio. This ratio has been shown to reduce the variation between people which may arise as a result of body size (Swaminathan et al., 1979).

The results in the groups were compared with the Mann Whitney $U$ test and by Students ' $t$ ' test. A probability value of 0.05 or less by both tests was taken to indicate a statistically significant different between the groups.

\section{Results}

Table 1 shows the daily mean values of blood glucose, ketones, glycerol and alanine concentrations and urine nitrogen creatinine ratio in the $\mathbf{3}$ groups of patients.

The blood glucose concentration increased in all 3 groups on the first postoperative day (day 1). The blood glucose concentration returned rapidly to the original value in the patients given saline or $30 \mathrm{~g}$ of glucose, whereas it remained raised for 3-4 days in the patients given $129 \mathrm{~g}$ of glucose.

In the patients given saline the blood ketones increased from $144 \mu \mathrm{mol} / \mathrm{l}$ before operation to $3323 \mu \mathrm{mol} / 1$ on the 5 th day and then fell rapidly towards the control values when oral feeding was started. The ketone concentration increased much less in the patients given $30 \mathrm{~g}$ of glucose and not at all in the patients given $129 \mathrm{~g}$ of glucose a day. The blood glycerol concentration in patients given $129 \mathrm{~g}$ of glucose a day was lower on the 3rd and 4th day after operation, but this difference was not statistically significant.

The alanine concentration in blood decreased progressively during the 5 days after operation equally in the 3 groups, and then increased after oral feeding was started. The nitrogen/creatinine ratio increased after surgery in the patients given saline. In patients given $30 \mathrm{~g}$ of glucose/day, the nitrogen/creatinine ratio was lower but the difference was not statistically significant. In patients given $129 \mathrm{~g}$ of glucose the values decreased after surgery and were significantly lower than in the other 2 groups on days 3,4 and 5 .

\section{Discussion}

During starvation there is an increase in blood ketone bodies, and a decrease in blood alanine (Ruderman, Aoki and Cahill, 1976). These changes happened in the surgical patients given saline, and could be due to starvation. Foster et al. (1978) have suggested, however, that the changes in the concentrations of ketones and alanine were greater during starvation than after surgery. Dudley, Masterton and Nayman (1965) and Dudley (1968) have suggested that the loss of nitrogen after surgery is also due to starvation. However, the nitrogen excretion increased after operation, whereas it decreases during starvation (Aoki et al., 1975; O'Connell et al.,

TABLE 1. Comparison of metabolite concentration in the three groups. Results are: mean ( \pm s.e.mean)

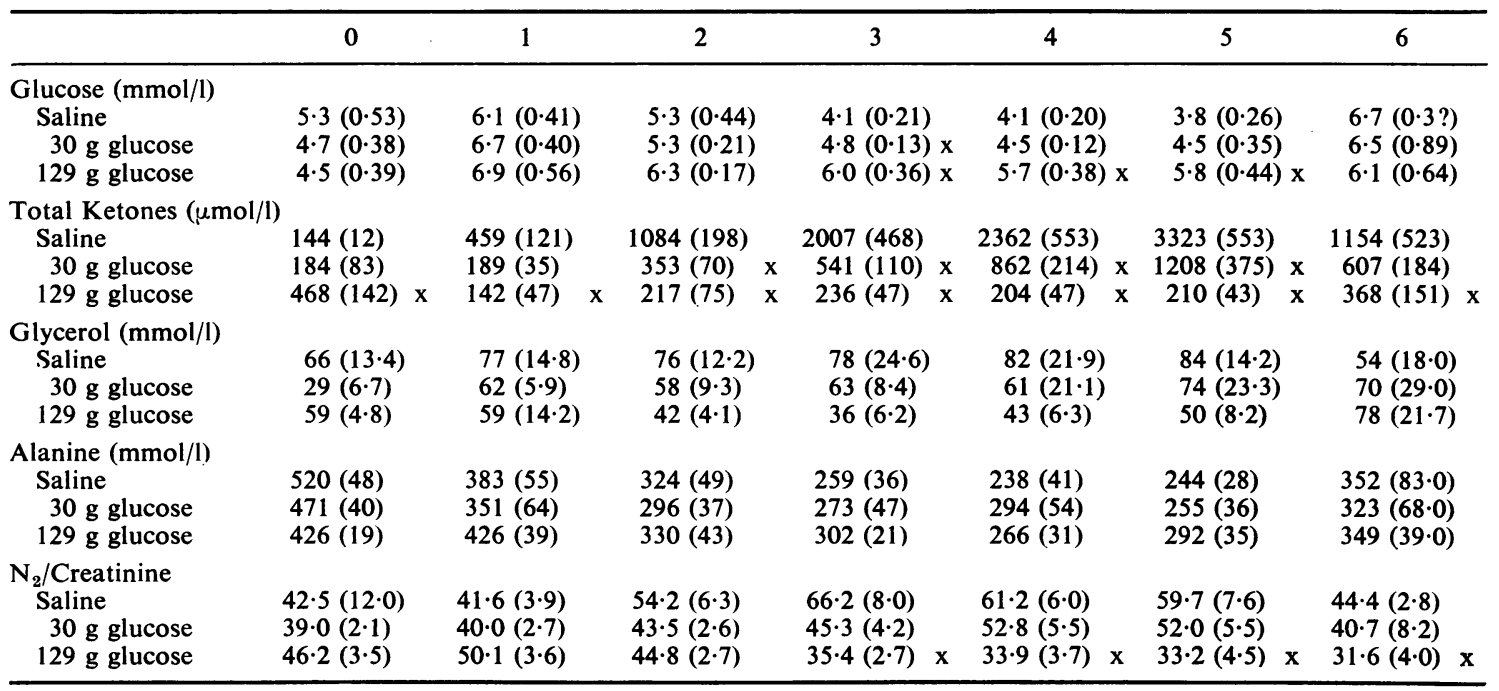

(x) Significantly different from the saline group by Students ' $t$ ' test and by Mann-Whitney $U$ test. 
1974; Ruderman et al., 1976) so that even after moderately severe surgery the nitrogen loss is much greater than in simple starvation of the same duration.

Muscle protein has been suggested as the origin of much of this excessive loss of nitrogen after surgery (Frawley, Antz and Howard, 1955; Cuthbertson, McGin and Robertson, 1939; Levenson and Watkin, 1959). Alanine is the principal amino acid released during muscle breakdown (Felig, 1975), so that if the nitrogen lost after surgery came from muscle there should be an increase in the blood alanine concentration. However, the alanine concentration decreased after surgery in the present patients as in previous reports (Dale et al., 1977; Schønheyder, Bone and Skjoldborg, 1974). The similar decrease in blood alanine after trauma has been attributed to an increased clearance of alanine (Alberti, Batstone and Johnston, 1977). The authors suggest that the changes in blood alanine concentration after surgery are due to changes in the rate of entry of alanine into the blood (Swaminathan, unpublished). The simultaneous decrease in alanine release and increase in urinary nitrogen excretion in the surgical patients given saline indicates that either an increased proportion of the urine nitrogen was coming from some source other than muscle or that a greater proportion of the alanine reaching the liver is metabolized to urea rather than being incorporated into proteins, i.e. a decrease in protein synthesis. The findings of O'Keefe et al. (1974) that protein synthesis is decreased after abdominal surgery supports the latter suggestion.

It is well known that body size can influence the loss of nitrogen after surgery (Moore and Ball, 1952). The authors have previously shown that nitrogen loss after surgery is related to fat free mass or $24 \mathrm{hr}$ urinary creatinine excretion, and expressing the results as nitrogen to creatinine ratio will reduce the variation due to body size (Swaminathan et al., 1979). Furthermore, this ratio will also reduce errors due to incomplete collection. This ratio was used in the present study to compare the nitrogen loss between groups.

Patients after surgery are regularly given glucose containing solutions and the metabolic state in these patients therefore includes the effects of glucose. The $4.3 \%$ glucose solution, which is the solution usually used in surgical practice, supplies $129 \mathrm{~g}$ of glucose $(2167 \cdot 2 \mathrm{~J})$ a day and was sufficient to raise the blood glucose, and prevent the rise in ketones and urine nitrogen (Table 1). The $1 \%$ solution which supplied $30 \mathrm{~g}$ of glucose $(502.1 \mathrm{~J})$ a day was sufficient to prevent the rise in ketones but it did not diminish the increase in nitrogen (Table 1). Neither solution had any effect on the fall in blood alanine. The reduction in blood ketones after $1 \%$ dextrose solution was not associated with any effect $\frac{2}{2}$ on blood glycerol and was therefore probably due $\frac{\mathrm{O}}{\mathrm{C}}$ to inhibition of ketone production in the liver rather than inhibition of lipolysis. The recent work of Elkeles, Chalmers and Hambley (1978) suggestso that this effect of glucose could be due to an $\bar{\sigma}$ increased secretion of insulin.

Conclusions reported in the 2 previous studies $\frac{\vec{D}}{8}$ on postoperative patients of the effect of dextrose on urine nitrogen excretion have been conflicting ${ }^{\infty}$ (Craig et al., 1977; Benotti et al., 1977), but as.

TABLE 2. Reduction in urine nitrogen excretion by glucose during fasting and after surgery

\begin{tabular}{|c|c|c|c|}
\hline & $\begin{array}{l}\text { Amount of } \\
\text { glucose }\end{array}$ & $\begin{array}{l}\text { Red } \\
\text { urin } \\
\%\end{array}$ & $\begin{array}{l}\text { ction in } \\
\text { nitrogen* } \\
\text { mmol/day }\end{array}$ \\
\hline $\begin{array}{l}\text { Starvation } \\
\text { O'Connell et al., } 1974\end{array}$ & 150 & $37 \cdot 0$ & 280 \\
\hline Benotti et al., 1977 & 150 & $35 \cdot 5$ & 315 \\
\hline Craig et al., 1977 & 150 & $33 \cdot 5$ & 350 \\
\hline Present series & 129 & $40 \cdot 5$ & 290 \\
\hline
\end{tabular}

* Reduction in urine nitrogen was calculated as the mean difference from the group given no calories.

Table 2 shows, the reduction in urine nitrogen those 2 studies was similar and the difference conclusion arose from interpretation of the statistic䆜. significance of the findings. The present results are similar to those in both the previous studies and when the 3 studies are combined the average reduction in urine nitrogen excretion is $300 \mathrm{mmol} / \stackrel{\varrho}{\varrho}$ day. This is similar to the reduction in urine nitrogen $\stackrel{\mathbb{Q}}{\varrho}$ in starved subjects given similar amounts of glucose $\overrightarrow{\overrightarrow{0}}$ (Table 2). This finding suggests that in the patients after surgery the glucose is preventing that part of the nitrogen excretion which is due to starvation and it has no effect on the excessive nitrogen excretion which happens as part of metabolic response to 3 . surgery. If this is the case, then it further suggests that these 2 components of nitrogen loss are due to different metabolic mechanisms.

\section{Acknowledgments}

We would like to thank the nursing staff of the surgical wards for their co-operation and Mrs A. Newill, Mrs D. Isherwood and Mrs J. Stevens for technical assistance.

\section{References}

Alberti, K.G.M.M., Batstone, G.F. \& Johnston, D.G. O (1977) Hormonal changes in trauma: role of cortisol. In: $\omega$ Nutritional Aspects of Care in the Critically Ill. (Ed by Richards, J.R. \& Kinney, J.M.), p. 225. Churchill Livingstone, Edinburgh.

ANNAN, W. (1974) The determination of lactate, pyruvate D-3-hydroxybutyrate and acetoacetate in blood using an enzyme reaction rate analyser. M.Sc. thesis, University of Leeds. 
Aoki, T.T., Muller, W.A., Brennan, H.F. \& Cahill, G.F. (1975) Metabolic effects of glucose in brief and prolonged fasted man. American Journal of Clinical Nutrition, 28, 507.

Benott, P.N., Blackburn, G.L., Miller, J.D.B., Bristrian, B.R., Flatt, J. \& Trerice, M. (1977) Role of branched chain amino acids (BCAA) intake in preventing muscle proteolysis. Surgical Forum, $27,7$.

Craig, R.P., Tweedle, D., Davidson, H.A. \& Johnston, I.D.A. (1977) Intravenous glucose, aminoacids and fat in the postoperative period. A controlled evaluation of each substrate. Lancet, ii, 8.

CuthBertson, D.P. (1936) Further observations on the disturbance of metabolism caused by injury with particular reference to the dietary requirements of fracture cases. British Journal of Surgery, 23, 505.

Cuthbertson, D.P., MCGin, J.L. \& Robertson, J.L. (1939) The effect of fracture of bone on the metabolism of the rat. Quarterly Journal of Experimental Physiology, 29, 18.

Dale, G., Young, G., Latner, A.L., Goode, A., Tweedle, D. \& Johnston, I.D.A. (1977) The effect of surgical operation on venous plasma free amino acids. Surgery, 81, 295.

DudLEY, H.A.F. (1968) Surgical convalescence. Journal of the Royal College of Surgeons of Edingburgh, 13, 1.

Dudley, H.A.F., Masterton, J.P. \& Nayman, J. (1965) Some problems at the frontiers of surgical survival. New Zealand Medical Journal, 64, 481.

Elkeles, R.S., Chalmers, R.A. \& Hambley, J. (1978) Evidence for an hepatic anti-ketogenic effect of insulin in man. Clinical Science and Molecular Medicine, 55, 499.

Felig, P. (1975) Amino acid metabolism in man. Annual Review of Biochemistry, 44, 933.

Foster, K.J., Alberti, K.G.M.M., Binder, C., Hinks, L.,
Karran, S., Talbot, S., Turnell, D. \& Ørskov, H (1978) The role of glucocorticoids and glucagon in the metabolic response to moderate injury. Clinical Science, 54, 4p.

Frawley, J.P., ANTz, C.P. \& Howard, J.M. (1955) Muscle metabolism and catabolism in combat casualties. Archives of Surgery, 71, 612.

Levenson, S.M. \& Watkin, D.M. (1959) Protein requirements in injury and certain acute and chronic diseases. Federation Proceedings, 18, 1155.

MOORE, F.D. (1953) Bodily changes in surgical convalescence. Annals of Surgery, 137, 289.

MOORE, F.D. \& BALL, M.R. (1952) In: The Metabolic Response to Injury. (Ed by Thomas, Charles C.T.) Springfield, Illinois.

O'Connell, R.C., Morgan, A.P., Aoki, T.T., Ball, M.R. \& MOORE, F.D. (1974) Nitrogen conservation in starvation: Graded responses to intravenous glucose. Journal of Clinical Endocrinology and Metabolism, 39, 555.

O'Keefe, S.J.D., Sender, P.M. \& JAmes, W.P.T. (1974). 'Catabolic' loss of body nitrogen in response to surgery, Lancet, ii, 1035.

Ruderman, N.B., Aoki, T.T. \& Cahill Jr, G.F. (1976). In: Gluconeogenesis: Regulation in Mammalian Species. (Ed by Hanson, R.W. \& Mehlman, M.A.) John Wiley, New York.

SchøNheyder, F., Bone, J. \& SKJoldborg, H. (1974) Variations in plasma amino acid concentrations after abdominal surgical procedures. Acta chirurgica scandinavica, 140, 271.

Swaminathan, R., Bradley, J.A., Hill, G.L. \& Morgan, D.B. (1979) The nitrogen to creatinine ratio in untimed samples or urine as an index of protein catabolism after surgery. Postgraduate Medical Journal, 55, 558. 